\title{
Psychological distress during the initial COVID-19 pandemic in an Italian cohort of people living with HIV: an online survey
}

Valentina Delle Donne ( $\sim$ valentina.delledonne@unicatt.it)

Catholic University of Sacred Heart, Rome

Nicoletta Ciccarelli

Catholic University, Milan

Valentina Massaroni

Catholic University of Sacred Heart, Rome

Francesca Lombardi

Fondazione Policlinico Universitario A. Gemelli IRCCS, Rome

Silvia Lamonica

Fondazione Policlinico Universitario A. Gemelli IRCCS, Rome

Alberto Borghetti

Fondazione Policlinico Universitario A. Gemelli IRCCS, Rome

Massimiliano Fabbiani

University Hospital of Siena

Roberto Cauda

Fondazione Policlinico Universitario A. Gemelli IRCCS, Rome

Simona Di Giambenedetto

Fondazione Policlinico Universitario A. Gemelli IRCCS, Rome

Research Article

Keywords: COVID-19, pandemic, HIV, psychological impact, distress, mental health

Posted Date: January 28th, 2021

DOI: https://doi.org/10.21203/rs.3.rs-98904/v2

License: (c) (i) This work is licensed under a Creative Commons Attribution 4.0 International License. Read Full License 


\section{Abstract}

Our aim was to explore the psychological impact of the initial 2019 Coronavirus (COVID-19) pandemic in a cohort of people living with HIV (PLWH), a population at increased risk of psychological distress.

PLWH, treated at our unit, responded an online survey. Data on demographics, clinical and physical symptoms, contact history, as well as knowledge, concerns, precautionary measures and additional information required with respect to COVID-19 during the first phase of the pandemic in Italy were collected. Additionally, the Impact of Event Scale-Revised (IES-R) (identifying COVID-19 pandemic as specific traumatic life event) and the Depression, Anxiety and Stress Scale (DASS-21) were also administered.

Out of 98 participants, 44 (45\%) revealed from mild to severe psychological impact distress from COVID-19 according to IES-R. According to DASS-21, a lower percentage of significant levels of depression (14\%), anxiety (11\%) or stress (6\%) were reported. Higher education, unemployment, number of perceived physical COVID-19 symptoms, concerns contracting COVID-19 and the situation regarding the pandemic in Italy, and the need of additional information to prevent COVID-19 infection were positively associated to psychological distress. Moreover, female gender, older age, recent HIV diagnosis and unawareness of own viremia were associated to a higher psychological distress.

Almost half of our cohort experienced significant levels of distress related to the COVID-19 pandemic. Women, elderly patients and those with recent HIV diagnosis resulted to be the more psychological fragile subgroup. Our findings could help to identify patients in need of psychological interventions to improve wellbeing of PLWH.

\section{Introduction}

The 2019 Coronavirus Disease (COVID-19), spreading from Wuhan (China) at the end of 2019, became soon a pandemic. The World Health Organization declared the COVID-19 outbreak on Jan 30th 2020 an international public health emergency affecting nowadays more than 200 countries and territories around the world. Italy has been hit first in European and faced COVID-19 as one of the most affected areas. To deal with the spread of the pandemic, on March 9th 2020, the Italian Government settled several emergency containment measures, which began to be loosened only from May 4th onwards.

Evidence of the initial phase of the COVID-19 outbreak demonstrated a great negative psychological impact on individuals especially in worst hit countries [13]. Mental health outcomes seem to be related to many factors: widespread contagion, containment and prevention measures such as self-isolation, social distancing, lockdown, and socio-economic impact [4-7]. Given the unprecedented nature of the COVID-19 pandemic, an increase in anxiety has been prevalent worldwide [8].

A review [3] about mental health outcomes of the COVID-19 pandemic on the general Chinese population identified a wide list of negative psychological responses such as anxiety, depression, stress, insomnia, indignation, worries about their own and family health, sensitivity to social risks, life dissatisfaction, phobias, avoidance, social functioning impairment, compulsive behaviour and physical symptoms [9-13]. Consistent predictors of psychological distress were identified such as female gender, higher age, specific physical symptoms, poor self-rated health status, the need of additional information with respect to COVID-19 (for example about precautionary measures), the experience of relatives or acquaintances infected with COVID-19, and medical history of chronic illness [11,13-15].

In Italy, a relevant percentage of the general population (38\%) have experienced from mild to to-severe psychological distress during the early phase of the COVID-19 outbreak [16], and evidence suggests a higher proportion compared to other European countries [17-19]. Furthermore, high rates of negative mental health outcomes, including post-traumatic stress symptoms and anxiety, were found [20].

A history of medical issues is among the predictors of psychological distress and could serve as an indicator to identify groups at higher risk of distress and in need for tailored psychological interventions [3].

Indeed, the Centre for Disease Control and Prevention highlighted that individuals with chronic health conditions, such as people living with HIV (PLWH), may develop a stronger stress response than the rest of the population [21].

Although there is no clear evidence that the risk of COVID-19 infection is higher among PLWH compared to the general population [22], to cope with COVID-19 outbreak might have significant effects on the biological, psychological and social aspects of their lives [8].

Firstly, outpatients' visits and treatment have been interrupted or postponed because of the lockdown [8] and the fear of contracting COVID-19 has led to decreased engagement with care among PLWH in several countries [23-27]. Additionally to complications related to HIV disease progression, an incorrect management of HIV could lead to an increased risk contracting COVID-19 and experiencing complications. [8].

Furthermore, the current pandemic is a significant stressor and could increase the risk of mental health concerns among PLWH [28].

Depression is the most common mental health disorder among PLWH [29], being two to four times more frequent than in HIV-negative people [30-32]. Symptoms of depression may be exacerbated by loneliness due to physical distancing necessary to contain COVID-19 and may have adverse effects on treatment adherence [33-35]. 
Additionally, COVID-19 is assumed to function in a syndemic framework "that is two or more epidemics interacting synergistically to produce an increased burden of disease in a population" [36] with several health challenges faced by PLWH including HIV itself, chronic non-communicable diseases, mental health burden, substance abuse, and other infections [37,38].

Therefore, due to the syndemic framework, the exposition to mental health issues $[39,40]$ and to a chronic illness [8,41,42], PLWH seem to be a group at greater risk for psychological distress during COVID-19 pandemic.

Currently, only few data exists about mental health of PLWH during COVID-19 pandemic reporting elevated levels of anxiety [43], and showing that COVID-19 and associated restrictive measures seem detrimental to the well-being and follow-up of PLWH [44]. Our aim was to better explore the psychological impact of COVID-19 on an Italian cohort of PLWH and to assess the possible risk and protective factors, in order to tailor specific psychological interventions.

\section{Materials And Methods}

\section{Participants}

In this cross-sectional study, PLWH followed at Infectious Diseases Institute of the Fondazione Policlinico Universitario A. Gemelli IRCCS of Rome, responded an online survey between May 9th and 25th 2020. This timeframe was chosen to assess participants' responses at the end of the first phase of the COVID-19 pandemic, following the Italian Government Decree of May 4th 2020, which began to loosen emergency containment measures. Exclusion criteria were age $<18$ years and difficulties with the Italian language.

All participants volunteered and did not receive any financial remuneration for participating. The institutional ethics committee approved the study protocol (ID number 3123). All procedures performed were in accordance with the ethical standards of the institutional and national research committee and with the 1964 Helsinki Declaration and its later amendments or comparable ethical standards. Informed consent was obtained from all participants included in the study.

Each participant completed a 105-item online survey adapted from Wang C et al. (2020) [11], in which data on demographic, clinical and COVID-related variables were collected.

Demographic and HIV-associated clinical variables

Data were collected on gender, age, education, employment status, sexual orientation, presence of a stable relationship (cohabitant or married), parenthood, time from HIV diagnosis, time from first combined Antiretroviral Treatment (cART), HIV-1 plasma viral load and adherence to cART in the last month (using a Likert scale from 1 [very bad] to 10 [excellently]).

\section{Physical health status variables}

We gathered information regarding health service utilization, including medical consultation, hospital admission, COVID-19 testing and quarantine. Moreover, physical symptom variables included fever, chills, headache, myalgia, cough, breathing difficulty, dizziness, coryza, sore throat, and the triad of fever, cough and difficult breathing. Moreover, a self-report judgment about own health-state choosing one of the following answers (poor, passable, good, very good or excellent) was asked.

\section{Contact history variables}

We asked if the respondents had contacts with individuals with suspected or confirmed COVID-19 infection or with infected materials (surfaces, objects, utensils).

\section{Knowledge and concerns about COVID-19 variables}

Regarding knowledge of COVID-19, we collected data about respondents' habits staying informed about the pandemic such as infection numbers, hospitalizations, deaths, main source of health information, satisfaction level of health information (using a Likert scale from 1 [not satisfied] to 10 [extremely satisfied]), knowledge about transmission roots and likelihood of surviving if infected with COVID-19 (using the following options: no chance, unlikely, likely, very likely and highly likely). COVID-19 concerns were investigated as follows: level of confidence in the own doctor's ability to diagnose COVID-19 (using a Likert scale from 1 [no trust] to 10 [full confidence]), concern regarding COVID-19 situation in Italy, concerns getting infected yourself or family members getting infected with COVID-19 (using a Likert scale from 1 [no concern] to 10 [extremely concern]), and feeling excessively worried about the pandemic (using the following options: always, mostly, sometimes, occasionally and never). 
We investigated precautionary COVID-19 measures such as hand hygiene immediately after coughing, rubbing nose, sneezing, touching contaminated objects, avoiding to share utensils during meals, covering mouth when coughing and sneezing, wearing masks regardless of the presence or absence of symptoms (choosing one of the following answers: always, mostly, sometimes, occasionally and never), and average number of hours staying at home per day to avoid COVID-19 infection.

\section{Additional information required with respect to COVID-19}

Further data were collected about the pandemic trend, more details on symptoms, additional advices on prevention, routes of transmission, treatment and the availability of medicines/vaccines, further regular updates on the state of pandemic and the number of people infected in their location and on the management of the outbreak in foreign countries, and more tips for moving from home safely during the outbreak.

Psychological impact of the COVID-19 pandemic and mental health status measures

To measure the psychological impact of the COVID-19 pandemic, the Impact of Event Scale-Revised (IES-R) was administered [45]. The IES-R is a 22-items self-report measure designed to assess current subjective distress for a specific traumatic life event, according to the DSM-IV symptoms of Post Traumatic Stress Disorder. Respondents were asked regarding a specific stressful life event and to indicate how much distressed they experienced during the past seven days. In our survey, the stressful event was the COVID-19 pandemic. The IES-R was constructed with three subscales: intrusions e.g., repeated thoughts about the trauma, avoidance e.g., effortful avoidance of situations that serve as reminders of the trauma, and physiological hyperarousal e.g., irritability, hypervigilance and difficulty concentrating [46]. Items were rated on a 5-point scale ranging from 0 ("not at all") to 4 ("extremely"). The IES-R yields a total score (ranging from 0 to 88) with a higher score indicating a greater psychological impact [47-48]. Mean scores can also be calculated for each subscale (range 0-4) and lower score means smaller psychological impact [49].

To measure mental health status the Depression, Anxiety and Stress Scale-21 (DASS-21) was administered [50,51]. The DASS-21 is a set of three self-report scales designed to measure the emotional states of depression, anxiety, and stress. The first subscale (DASS-Depression) measures loss of selfesteem/incentives and depressed mood. The second subscale (DASS-Anxiety) measures fear and anticipation of negative events. The third subscale (DASSStress) measures the persistent state of over arousal and low frustration tolerance. The higher the score, the more severe the emotional distress [52].

The principal difference between IES-R and DASS-21 (stress subscale) is that the former assesses the psychological impact of a specific traumatic event, while the latter does not identify any specific event. To clarify, we indicated the construct measured by IES-R (i.e. concerning a specific event) as "distress", and that one measured by DASS-Stress subscale (i.e. do not related to any specific event) as "stress".

\section{Statistical analysis}

Descriptive statistics were calculated for qualitative and quantitative variables. We performed binary logistic regression analyses to explore factors significantly associated with mild-to-severe psychological distress measured by IES-R as well as with mild-to-extremely severe levels of depression, anxiety, and stress measured by DASS-21. A two-tailed $p$ value of less than 0.05 was considered statistically significant.

Due to high inter-correlations between the collected COVID-19 related variables, only univariate analyses were run for these factors.

All analyses were performed using SPSS version 21.0 software package (SPSS Inc., Chicago, IL).

\section{Results}

Demographic and clinical characteristics

Ninety-eight Italian PLWH on cART completed the survey of which $75.5 \%(n=74)$ were male, aged between 51 and 60 years (46\% [ $n=45]$ ), with high school degree $(41 \%[n=40])$ and employed $(62.2 \%[n=61])$.

Sixty-four (65.3\%) and fifty-nine (60\%) of respondents showed a time >10 years from HIV diagnosis and from first cART, respectively. Overall, $74.5 \%$ ( $\mathrm{n}=73$ ) of patients reported HIV-RNA<50 copies/mL and the mean adherence to cART was 9.48 (standard deviation, SD 1.10) on a 0-10 scale. Full demographic and clinical characteristics are summarized in Table 1.

\section{Psychological impact and mental health evaluation}

According to the IES-R, 45\% ( $n=44)$ of PLWH revealed mild to severe psychological impact of COVID-19 on their life. We considered the mean scores of the IES$\mathrm{R}$ subscales within the group of patients with mild to severe effect and the highest mean score was observed in the physiological hyperarousal subscale (1.84, SD 0.74$)$ followed by the avoidance subscale $(1.78, S D 0.46)$ and the intrusion subscale $(1.64$, SD 0.62$)$, all indicating few symptoms of post-traumatic stress. 
Regarding the DASS-21, $14.3 \%(n=14), 11.2 \%(n=11)$ and $6.1 \%(n=6)$ of PLWH obtained a score suggesting the presence of mild to severe levels of depression, anxiety and stress, respectively; no patient obtained a extremely severe score.

Complete descriptive statistics of IES-R and DASS-21 item scales are shown in Table 2.

Demographic and clinical factor associated to psychological impact and mental health evaluation

We explored factors associated to significant mild-to-severe levels of distress measured by IES-R, and to mild-to-severe levels of depression, anxiety and stress measured by DASS-21. For simplicity, only significant associations at multivariate analyses where reported. A full description of these logistic regression analyses is shown in Table 3a and 3b.

In multivariate logistic regression analyses, female gender (OR 2.99; $95 \%$ confidence intervals [Cl] $0.99 / 8.98 ; p=0.051)$ showed a good trend towards a statistical significant correlation with mild-to-severe levels of distress (IES-R), while age range 41 to 50 (OR 0.08; $95 \% \mathrm{Cl} 0.01 / 0.51 ; \mathrm{p}=0.007)$ and 51 to 60 (OR $0.20 ; 95 \% \mathrm{Cl} 0.04 / 0.95 ; \mathrm{p}=0.044)$ compared to be older than 60 years, a secondary $(\mathrm{OR} 0.17 ; 95 \% \mathrm{Cl} 0.03 / 0.99 ; p=0.049)$, upper $(\mathrm{OR} 0.12 ; 95 \% \mathrm{Cl} 0.02 / 0.65 ; p=$ $0.014)$ and bachelors (OR $0.14 ; 95 \% \mathrm{Cl} 0.02 / 0.82 ; \mathrm{p}=0.030)$ school degree compared to postgraduate degree, and being employed $(\mathrm{OR} 0.23 ; 95 \% \mathrm{Cl} 0.07 / 0.75$; $\mathrm{p}=0.016)$ or retired $(\mathrm{OR} 0.12 ; 95 \% \mathrm{Cl} 0.01 / 0.79 ; \mathrm{p}=0.028)$ compared to being unemployed resulted as protective factors.

Furthermore, a time between 5 and 10 years from HIV diagnosis was significantly correlated to mild-to-severe levels of depression (DASS-21) (OR 10.02; 95\% $\mathrm{Cl} 2.39 / 41.95 ; \mathrm{p}=0.002)$ compared to a time $>10$ years, and unawareness of own viremia was a factor for mild-to-severe levels of anxiety (DASS-21) (OR 6.15; $95 \% \mathrm{Cl} 1.23 / 30.61 ; p=0.027)$.

Others factors related to the severity of HIV infection (time from first CART, HIV-1 plasma viral load and adherence to cART in the last month) were not found to be associated with psychological impact and mental health evaluation.

\section{Contact history variables and physical health status}

A detailed description of contact history and physical health status is reported in Table 4.

Only $4.1 \%(n=4)$ of participants had contacts with individuals with suspected or confirmed COVID-19 infection and 7.1\% $(n=7)$ with infected materials.

Seventy-six (77.5\%) participants reported good or very good health status and only two (2\%) had been under quarantine by a health authority. The most frequent physical symptom reported was headache (33.7\%).

For conciseness, only significant associations at logistic univariate analyses where reported. Contact history variables were not significantly associated to IES-R and DASS-21 scores. Instead, the number of possible COVID-19 symptoms was positively associated to mild-to-severe psychological distress measured by IES-R (OR 1.42; 95\% Cl 1.07/1.88; $p=0.014)$, and of mild-to-severe depression (OR 1.40; 95\% Cl 1.03/1.90; $p=0.032)$, anxiety $(\mathrm{OR} 1.50 ; 95 \% \mathrm{Cl} 1.08 / 2.09 ; \mathrm{p}=$ $0.016)$ and stress (OR 1.56; $95 \% \mathrm{Cl} 1.03 / 2.34 ; \mathrm{p}=0.032)$ measured by DASS-21. A complete description of associations between psychological impact and mental health measures and each physical symptoms complained is shown in Table 5.

Knowledge and concerns about COVID-19 variables

A detailed description of knowledge and concerns about COVID-19 is reported in Table 6. About $94 \%$ ( $n=92)$ of the respondents usually kept themselves informed about COVID-19 outbreak. The most common source of health information was from television $(59.2 \%, \mathrm{n}=58)$ and the mean satisfaction with the amount of available health information was 6.48 (SD 2.08) on a 0-10 scale.

The majority of participants knew routes of transmission of COVID-19: $87 \%(n=85)$ agreed with route of transmission through droplets and $85 \%$ ( $n=83$ ) through contaminated objects. About $61 \%(n=60)$ of respondents considered very likely surviving if infected with COVID-19.

Regarding COVID-19 pandemic concerns, mean concerns of situation in Italy was 6.39 (SD 2.47), and 37\% ( $=36$ ) of respondents sometimes felt too much unnecessary worry about the pandemic.

For brevity, only significant associations at logistic univariate analyses where reported. Staying informed about COVID-19 outbreak was associated to a lower mild-to-severe levels of depression measured by DASS-21 (OR 0.13; 95\% CI 0.02/0.75; $p=0.023$ ), while increased concern to contract COVID-19 was a factor for mild-to-severe levels of psychological distress measured by IES-R (OR 1.23; 95\% CI 1.04/1.45; $\mathrm{p}=0.012)$, and for mild-to-severe levels of depression (OR $1.35 ; 95 \% \mathrm{Cl} 1.03 / 1.78 ; \mathrm{p}=0.028)$ and stress (OR 2.04; $95 \% \mathrm{Cl} 1.13 / 3.70 ; \mathrm{p}=0.017$ ) measured by DASS-21.

Moreover, wider concern about COVID-19 in Italy was associated to mild-to-severe psychological distress measured by IES-R (OR 1.29; $95 \%$ CI 1.07/1.55; $p=$ 0.007). 
Table 7 details precautionary measures adopted by participants.

The two most frequently adopted precautionary measures were always perform hand hygiene with soap and water ( $84 \%$, $\mathrm{n}=82)$, and after touching contaminated objects $(80 \%, \mathrm{n}=79)$.

Precautionary variables were not significantly correlated to psychological distress levels measure by IES-R and depression, anxiety and stress levels measured by DASS-21.

\section{Additional information required with respect to COVID-19}

Table 8 describes additional information required with respect to COVID-19 reported by participants. For simplicity, only significant associations at logistic univariate analyses where reported. Requiring further information on prevention measures of COVID-19 infection was associated to mild-to-severe levels of anxiety (OR 5.06; 95\% Cl 1.25/20.51; $\mathrm{p}=0.023)$ measured by DASS-21.

\section{Discussion}

We found that, during the first 2 months after the beginning of COVID-19 pandemic in Italy, almost half of our PLWH cohort experienced mild to severe psychological distress according to the IES-R scale, which measures emotional states referring to a specific event. This percentage is higher compared to that observed in previous studies reporting $37 \%$ and $38 \%$ of distress in the general population $[16,20]$, which confirms that PLWH might be a more fragile population in need of particular care.

Similarly to a previous Chinese survey [11], a lower percentage of our sample complained elevated levels of depression, anxiety and stress, which was assessed with DASS-21. This result might be explainable with the fact that this scale investigates emotional states not referring to a specific event and, consequently, it could be less sensitive in case of pandemic-related psychological impact.

In accordance with previous evidence $[3,11,14,16,18,19,8,53]$, we confirm that several factors are associated with a higher risk of negative psychological impact during the COVID-19 pandemic. To be more specific, we found that female gender was associated with a good trend towards a statistical significance with increased distress [54]. In addition, higher age confirmed its negative association with mental health, probably because the physical distancing due to lockdown has exacerbated isolation and loneliness [55-56] especially among elderly people [38]. In our study, higher education was correlated with distress. However, in literature, inconsistent results can be found [3]. Indeed both high [13-14] and low [11] education levels have been found as possible risk factors for adverse psychological outcomes. Additionally, we found unemployment a risk factor for distress, suggesting that the pandemic's disproportionate impact on economically disadvantaged persons may have amplified pre-existing health disparities within the HIV epidemic [8]. Furthermore, a greater need of additional health information about COVID-19 prevention measures was associated to negative mental health outcomes, suggesting the usefulness of providing accurate health information during the pandemic to reduce the impact of rumours by government and health authorities [5]. On the other hand, PLWH staying informed about COVID-19 outbreak showed a lower depression levels.

To experience higher number of possible COVID-19 physical symptoms, higher concerns contracting COVID-19 or regarding pandemic evolution in Italy were correlated to adverse psychological impact.

Among HIV factors, fewer years from HIV diagnosis were associated with a higher risk of depression, maybe due to an increased mental health burden during the first years after HIV diagnosis [40], and unawareness of own viremia caused higher levels of anxiety. In other words, "those who perceive their own health as poor might feel more vulnerable when facing a new disease" [57]. In our sample, other factors related to the severity of HIV infection associated with mental health evaluation were not identified, maybe due to the high prevalence of patients with full adherence to cART and virally suppressed.

Our study has some limitations, as the cross-sectional study design and future longitudinal studies are needed to confirm and check the progress of our findings. Secondly, further investigations including a HIV-negative control group would be useful to check for any differences in psychological impact or mental health status between PLWH and the general population. Moreover, reliability of self-administered questionnaires may be partially biased because of socially desirable responses. Furthermore, we used an online survey leaving a population not using network devices unexplored, and due to requirements on anonymity and confidentiality, some demographics and clinical data we were not available. Since all of our patients were over 30 years old, further investigations including younger PLWH are needed; however, an older cohort is more representative for the current Italian population with HIV infection.

In conclusion, this study shows that almost half of an Italian cohort of PLWH experienced from mild to severe adverse psychological impact related to the first stage of the COVID-19 pandemic. Taken together, our findings suggest that among PLWH, women and elderly, and those with recent HIV diagnosis might be at greater risk of distress from COVID-19 might require particular care. Regular health check-ups and accurate information about COVID-19 in the media appear important to prevent stress and anxiety. Our results describe a first picture of the psychological impact of COVID-19 on an Italian cohort of PLWH. This overview could help to identify patients requiring support and highlights the importance to tailor specific psychological interventions to improve psychological wellbeing of PLWH, especially during the COVID-19 crisis. To be more specific, during the COVID-19 pandemic, it could be necessary to implement a more modern model of care integrating special interventions like telepsychology, that is the provision of psychological services using telecommunication technologies [56]. To this purpose, health providers have to develop the knowledge, skills, and attitudes needed to utilize telehealth technologies by specific training according with the American Psychological Association's (APA) guidelines. [58]. 
Funding: No funds, grants, or other support was received. No institution or funding has been used as the financial resource of this study.

\section{Conclusions}

This study shows that almost half of an Italian cohort of PLWH experienced from mild to severe adverse psychological impact related to COVID-19 pandemic. Especially, women and those with more recent HIV diagnosis seem to be at greater risk of negative psychological outcomes. In conclusion, our results describe a first picture of the psychological impact of COVID-19 on an Italian sample of PLWH, and could help to identify patients most in need of support and highlight the importance to tailor specific psychological interventions to improve their psychological wellbeing.

\section{Declarations}

\section{Acknowledgement}

All authors contributed to the study conception and design. Material preparation, data collection and analysis were performed by Delle Donne Valentina, Massaroni Valentina and Ciccarelli Nicoletta. The first draft of the manuscAript was written by Delle Donne Valentina and all authors commented on previous versions of the manuscript. All authors read and approved the final manuscript. We would like to thank Franziska M. Lohmeyer, PhD, Fondazione Policlinico Universitario A. Gemelli, for her support revising our manuscript.

\section{Funding}

No funding was received for this study.

\section{Conflict of Interest}

AB fee for advisory board by ViiV Healthcare, personal fee by Janssen Cilag. MF received speakers' honoraria and support for travel to meetings from BristolMyers Squibb (BMS), Gilead, Janssen-Cilag, Merck Sharp \& Dohme (MSD), ViiV Healtcare, and fees for attending advisory boards from BMS, Gilead and Janssen-Cilag. SDG received speakers' honoraria and support for travel to meetings from Gilead, Janssen-Cilag (JC), Merck Sharp \& Dohme (MSD) and ViiV Healtcare. All other authors: none to declare.

\section{Author contributions}

All authors contributed to the study conception and design. Material preparation, data collection and analysis were performed by Delle Donne Valentina, Massaroni Valentina and Ciccarelli Nicoletta. The first draft of the manuscript was written by Delle Donne Valentina and all authors commented on previous versions of the manuscript. All authors read and approved the final manuscript.

\section{Ethics Approval and consent to participate}

All procedures performed in studies involving human participants were in accordance with the ethical standards of the institutional and national research committee and with the 1964 Helsinki Declaration and its later amendments or comparable ethical standards. The Study was approved by the Ethics Committee of the Catholic University of Sacred Heart, Rome, Italy. Informed consent was obtained from all individual participants included in the study.

\section{Consent for publication}

Not applicable.

\section{Availability of data and materials}

The datasets generated for this study are available on request to the corresponding author.

\section{Code availability}

Not applicable.

\section{References}

[1] Fiorillo A, Gorwood P. The consequences of the COVID-19 pandemic on mental health and implications for clinical practice. Eur Psychiatry 2020; 63 (1), e32.

[2] Kang L, Ma S, Chen M, et al. Impact on mental health and perceptions of psychological care among medical and nursing staff in Wuhan during the 2019 novel coronavirus disease outbreak: a cross-sectional study. Brain Behav Immun 2020; 87, 11-17.

[3] Talevi D, Socci V, Carai M, et al. Mental health outcomes of the CoViD-19 pandemic. Riv Psichiatr 2020; 55 (3), 137-144.

[4] Brooks SK, Webster RK, Smith LE, et al. The psychological impact of quarantine and how to reduce it: rapid review of the evidence. Lancet 2020; 395 (10227), 912-920.

[5] Rubin JG. The psychological effects of quarantining a city. BMJ 2020; 368, m313. 
[6] Duan L, Zhu G. Psychological interventions for people affected by the CoViD-19 epidemic. Lancet Psychiatry 2020; 7, $300-302$.

[7] Ayittey FK, Ayittey MK, Chiwero NB, et al. Economic impacts of Wuhan 2019-nCoV on China and the world. J Med Virol 2020; 92, 473-475.

[8] Chenneville T, Gabbidon K, Hanson P, et al. The Impact of COVID-19 on HIV Treatment and Research: A Call to Action. Int J Environ Res Public Health 2020; 17 (12), 45-48.

[9] Li S, Wang Y, Xue J, et al. The Impact of CoViD-19 epidemic declaration on psychological consequences: a study on active weibo users. Int J Environ Res Public Health 2020; 17 (6), 2032.

[10] Liu N, Zhang F, Wei C, et al. Prevalence and predictors of PTSS during COVID- 19 outbreak in China hardest-hit areas: gender differences matter. Psychiatry Res 2020; 16 (287), 112921.

[11] Wang C, Pan R, Wan X, et al. Immediate psychological responses and associated factors during the initial stage of the 2019 coronavirus disease (COVID19) epidemic among the general population in China. Int J Environ Res Public Health 2020; 17, 1729.

[12] Cao W, Fang Z, Hou G, et al. The psychological impact of the CoViD-19 epidemic on college students in China. Psychiatry Res 2020; $287,112934$.

[13] Qiu J, Shen B, Zhao M, et al. A nationwide survey of psychological distress among Chinese people in the COVID-19 epidemic: Implication and policy recommendations. Gen Psychiatr 2020; 33, e100213.

[14] Wang Y, Di Y, Ye J, et al. Study on the public psychological states and its related factors during the outbreak of coronavirus disease 2019 (CoViD-19) in some regions of China. Psychol Health Med 2020; 1-10.

[15] Zhang Y, Ma ZF. Impact of the COVID-19 Pandemic on Mental Health and Quality of Life among Local Residents in Liaoning Province, China: A CrossSectional Study. Int J Environ Res Public Health 2020; 17 (7), 2381.

[16] Moccia L, Janiri D, Pepe M, et al. Affective temperament, attachment style, and the psychological impact of the COVID-19 outbreak: an early report on the Italian general population. Brain Behav Immun 2020; 87, 75-79.

[17] Jacobi F, Höfler M, Siegert J, et al. Twelve-month prevalence, comorbidity and correlates of mental disorders in Germany: The Mental Health Module of the German Health Interview and Examination Survey for Adults (DEGS1-MH). Int J Methods Psychiatr Res 2014; 23, $304-319$.

[18] Mazza C, Ricci E, Biondi S, et al. A Nationwide Survey of Psychological Distress among Italian People during the COVID-19 Pandemic: Immediate Psychological Responses and Associated Factors. Int J Environ Res Public Health 2020; 17 (9), 3165.

[19] Wittchen HU, Jacobi F, Rehm J, et al. The size and burden of mental disorders and other disorders of the brain in Europe. Eur Neuropsychopharmacol $2010 ; 21,655-679$.

[20] Rossi R, Socci V, Talevi D, et al. COVID-19 Pandemic and Lockdown Measures Impact on Mental Health Among the General Population in Italy. Front Psychiatry 2020; 11, 790.

[21] Centers for Disease Control and Prevention (CDC). Coronavirus Disease 2019 (COVID-19) in People with HIV. Available at: https://www.cdc.gov/coronavirus/2019-ncov/specific-group s/hiv.html. [accessed 23 March 2020].

[22] BHIVA- British HIV Association. News \& Media: EACS \& BHIVA Statement on risk of COVID-19 for people living with HIV. 2020. Available at: https://www.bhiva.org/EACS-BHIVA-Statement-on-risk-of-COVID-19-for-people-living-with-HIV.

[23] Kowalska JD, Skrzat-Klapaczynska A, Bursa D, et al. HIV care in times of the COVID19 crisis - where are we now in Central and Eastern Europe? Int J Infect Dis $2020 ; 96,311-314$.

[24] Ponticiello M, Mwanga-Amumpaire J, Tushemereirwe P, et al. "Everything is a mess": how COVID-19 is impacting engagement with HIV testing Services in rural southwestern Uganda. AIDS Behav 2020; 1-4.

[25] Ballester-Arnal R, Gil-Llario MD. The virus that changed Spain: impact of COVID-19 on people with HIV. AIDS Behav 2020; 1-5.

[26] Lodge 2nd W, Kuchukhidze S. COVID-19, HIV, and migrant workers: the double burden of the two viruses. AIDS Patient Care STDS 2020; $34,249-250$.

[27] Prabhu S, Poongulali S, Kumarasamy N. Impact of COVID-19 on people living with HIV: A review. J Virus Erad 2020; 6 (4), 100019.

[28] World Health Organization. 2019 Novel Coronavirus Global Research and Innovation Forum: Towards a Research Roadmap. 2020. Available at: https://www.who.int/who-documents-detail/2019-novelcoronavirus-overview-of-the-state-of-the-art-and-outline-of-key-knowledge-gaps-slides [accessed 27 April 2020].

[29] Nanni MG, Caruso R, Mitchell AJ, et al. Depression in HIV infected patients: A review. Curr Psychiatry Rep 2015; 17, 530.

[30] Bing EG, Burnam MA, Longshore D, et al. Psychiatric disorders and drug use among human immunodeficiency virus-infected adults in the United States. Arch Gen Psychiatry 2001; 58, 721-728. 
[31] Ciesla JA, Roberts JE. Meta-Analysis of the relationship between HIV infection and risk for depressive disorders. Am J Psychiatry 2001; 158, 725-730.

[32] Nacher M, Adriouch L, Godard Sebillotte C, et al. Predictive factors and incidence of anxiety and depression in a cohort of HIV-positive patients in French Guiana. Aids Care 2010; 22, 1086-1092.

[33] Gonzalez JS, Batchelder AW, Psaros C, et al. Depression and HIV/AIDS treatment nonadherence: A review and meta-analysis. J Acquir Immune Defic Syndr $2011 ; 58,181-187$.

[34] Orban L, Stein R, Koenig L, et al. Coping strategies of adolescents living with HIV: Disease-specific stressors and responses. Aids Care 2010; 22 , 420-430.

[35] Blashill AJ, Perry N, Safren SA. Mental health: A focus on stress, coping, and mental illness as it relates to treatment retention, adherence, and other health outcomes. Curr Hiv Aids Rep 2011; 8, 215-222.

[36] Singer M. Pathogen-pathogen interaction: a syndemic model of complex biosocial processes in disease. Virulence 2010; 1 (1), 10-8.

[37] Halkitis PN, Moeller RW, Siconolfi DE, et al. Measurement model exploring a syndemic in emerging adult gay and bisexual men. AIDS Behav 2013; 17 (2), $662-673$.

[38] Shiau S, Krause KD, Valera P, et al. The Burden of COVID-19 in People Living with HIV: A Syndemic Perspective. AIDS Behav 2020; 24 (8), $2244-2249$.

[39] Brandt C, Zvolensky MJ, Woods SP, et al. Anxiety symptoms and disorders among adults living with HIV and AIDS: A critical review and integrative synthesis of the empirical literature. Clin Psychol Rev 2016; 51, 164-184.

[40] Lynn C, Bradley-Klug K, Dedrick R, et al. Mental health screening in integrated care settings: Identifying rates of depression, anxiety, and posttraumatic stress among youth with HIV. AIDS Care 2018; 17 (3), 1-7.

[41] Gebo KA. Epidemiology of HIV and response to antiretroviral therapy in the middle aged and elderly. J Aging Health $2008 ; 4,615-627$.

[42] Nachega JB, Hsu AJ, Uthman OA, et al. Antiretroviral therapy adherence and drug-drug interactions in the aging HIV population. AIDS 2012; 26 , S39-S53.

[43] Kuman TunÇel Ö, PullukÇu H, Erdem HA, et al. COVID-19 related anxiety in people living with HIV: An online cross-sectional study. Turk J Med Sci 2020. Epub ahead of print. PMID: 32777899.

[44] Siewe Fodjo JN, Faria de Moura Villela E, et al. Impact of the COVID-19 pandemic on the medical follow-up and psychosocial well-being of people living with HIV: A cross-sectional survey. J Acquir Immune Defic Syndr 2020; 85 (3), 257-262.

[45] Christianson S, Marren J. The Impact of Event Scale - Revised (IES-R). Medsurg Nurs 2012; 21 (5), 321-322.

[46] Gayle Beck J, Grant DM, Read JP, et al. The Impact of Event Scale-Revised: Psychometric properties in a sample of motor vehicle accident survivors. J Anxiety Disord 2008; 22 (2), 187-198.

[47] Reynolds DL, Garay JR, Deamond SL, et al. Understanding, compliance and psychological impact of the SARS quarantine experience. Epidemiol Infect $2008 ; 136,997-1007$.

[48] Creamer M, Bell R, Failla S. Psychometric properties of the Impact of Event Scale-Revised. Behav Res Ther 2003; 41, 1489-1496.

[49] Weiss DS, Marmar CR. The impact of event scale - revised. In: Assessing psychological trauma and PTSD (Wilson JP, Keane TM, Eds). Guilford Press, New York; 1997: 399-411.

[50] Henry JD, Crawford JR. The short-form version of the Depression Anxiety Stress Scales (DASS-21): Construct validity and normative data in a large nonclinical sample. Br J Clin Psychol 2005; 44, 227-239.

[51] Norton PJ. Depression Anxiety and Stress Scales (DASS-21): psychometric analysis across four racial groups. Anxiety Stress Coping $2007 ; 20,253-265$.

[52] Oei T, Sawang S, Wah Goh Y, et al. Using the Depression Anxiety Stress Scale 21 (DASS-21) across cultures. Int J Psycho 2013; 6, 1018-1029.

[53] Ho CSH, Tan E, Ho R, et al. Relationship of anxiety and depression with respiratory symptoms: Comparison between depressed and non-depressed smokers in Singapore. Int J Environ Res Public Health 2019; 16 (1), 163.

[54] Sareen D, O'Rourke JG, Meera P, et al. Targeting RNA foci in iPSC-derived motor neurons from ALS patients with a C90RF72 repeat expansion. Sci Transl Med 2013; 5 (208), 208ra149.

[55] Armitage R, Nellums LB. COVID-19 and the consequences of isolating the elderly. Lancet Public Health 2020; 5 (5), e256.

[56] Brooke J, Jackson D. Older people and COVID-19: Isolation, risk and ageism. J Clin Nurs 2020; 29 (13-14), 2044-2046.

[57] Hatch R, Young D, Barber V, et al. Anxiety, depression and post-traumatic stress disorder after critical illness: AUK-wide prospective cohort study. Crit Care $2018 ; 22,310$. 
[58] American Psychological Association's Joint Task Force for the Development of Telepsychology Guidelines for Psychologists. Guidelines for the Practice of Telepsychology. 2013. Available online: https://www.apa. org/practice/guidelines/telepsychology (accessed on 2 May 2020).

\section{Tables}

Table 1 Demographic and clinical characteristics

\begin{tabular}{|c|c|}
\hline Variables & N (\%) or median*(IQR) \\
\hline Male gender & $74(75.5)$ \\
\hline \multicolumn{2}{|l|}{ Age, years } \\
\hline $31-40$ & $13(13.3)$ \\
\hline $41-50$ & $24(24.5)$ \\
\hline $51-60$ & $45(45.9)$ \\
\hline$>60$ & $16(16.3)$ \\
\hline \multicolumn{2}{|l|}{ Education } \\
\hline Lower secondary school & $24(24.5)$ \\
\hline Upper secondary school & $40(40.8)$ \\
\hline Bachelors Degree & $23(23.5)$ \\
\hline Postgraduate & $11(11.2)$ \\
\hline \multicolumn{2}{|l|}{ Sexual orientation } \\
\hline Heterosexual & $46(46.9)$ \\
\hline Homosexual & $52(53.1)$ \\
\hline \multicolumn{2}{|l|}{ Stable Relationship } \\
\hline Yes & 39 (39.8) \\
\hline No & $59(60.2)$ \\
\hline \multicolumn{2}{|l|}{ Children } \\
\hline Yes & $31(31.6)$ \\
\hline No & $67(68.4)$ \\
\hline \multicolumn{2}{|l|}{ Employment status } \\
\hline Unemployed & $23(23.5)$ \\
\hline Retired & $14(14.3)$ \\
\hline Employed & $61(62.2)$ \\
\hline \multicolumn{2}{|l|}{ Years from HIV diagnosis } \\
\hline$<5$ years & $16(16.3)$ \\
\hline 5-10 years & $18(18.4)$ \\
\hline$>10$ years & $64(65.3)$ \\
\hline \multicolumn{2}{|c|}{ Time from starting first cART regimen } \\
\hline$<5$ years & $17(17.3)$ \\
\hline 5-10 years & $22(22.4)$ \\
\hline$>10$ years & $59(60.2)$ \\
\hline Own viremia knowledge & $90(91.8)$ \\
\hline HIV-RNA <50 copies/mL & $73(74.5)$ \\
\hline Adherence*, on a 0-10 scale & $10(9-10)$ \\
\hline
\end{tabular}

Table 2 
Levels of Depression, Anxiety, Stress and Distress in the Study Population ( $N=98)$.

\begin{tabular}{|c|c|c|}
\hline Variables & Mean score (SD) & $\mathrm{N}(\%)$ \\
\hline DASS-21 Depression Subscale & $4.47(4.17)$ & \\
\hline Average (0-9) & & $84(85.7)$ \\
\hline Mild (10-12) & & $9(9.2)$ \\
\hline Moderate (13-20) & & $4(4.1)$ \\
\hline Severe (21-27) & & $1(1)$ \\
\hline Extremely Severe (28-42) & & $0(0)$ \\
\hline DASS-21 Anxiety Subscale & $2.36(3.04)$ & \\
\hline Average $(0-6)$ & & $87(88.8)$ \\
\hline Mild (7-9) & & $7(7.1)$ \\
\hline Moderate (10-14) & & $3(3.1)$ \\
\hline Severe (15-19) & & $1(1)$ \\
\hline Extremely Severe (20-42) & & $0(0)$ \\
\hline DASS-21 Stress Subscale & $4.14(3.18)$ & \\
\hline Average (0-10) & & $92(93.9)$ \\
\hline Mild (11-18) & & $6(6.1)$ \\
\hline Moderate (19-26) & & $0(0)$ \\
\hline Severe (27-34) & & $0(0)$ \\
\hline Extremely Severe (35-42) & & $0(0)$ \\
\hline IES-R avoidance subscale* & $1.78(0.46)$ & \\
\hline IES-R intrusion subscale* & $1.64(0.62)$ & \\
\hline IES-R hyperarousal subscale* & $1.84(0.74)$ & \\
\hline IES-R total score & $22.62(15.84)$ & \\
\hline Average (range 0-23) & & $54(55.1)$ \\
\hline Mild (range 24-32) & & $19(19.4)$ \\
\hline Moderate (range 33-36) & & $3(3.1)$ \\
\hline Severe (>37) & & $22(22.4)$ \\
\hline
\end{tabular}

Abbreviations: N number, SD standard deviation, IES-R Impact of Event Scale-Revised, DASS-21 Depression, Anxiety and Stress Scale. $* 0=$ No symptoms $1=$ Few symptoms $2=$ Moderate symptoms $3=$ A High level of symptoms $4=$ An Extremely high level of symptoms

Table 3a. Demographic and clinical factors associated to mild-to-extremely severe levels of distress measured by IES-R. 
IES-R

UNIVARIATE ANALYSIS

MULTIVARIATE

ANALYSIS

\begin{tabular}{|c|c|c|c|c|c|c|}
\hline Variables & OR & $95 \% \mathrm{CI}$ & $\mathrm{p}$ & OR & $95 \% \mathrm{CI}$ & $\mathrm{p}$ \\
\hline Sex (Female vs Male) & 2.58 & $1.00 / 6.68$ & $0.050 *$ & 2.99 & $0.99 / 8.98$ & $0.051 *$ \\
\hline \multicolumn{7}{|l|}{ Age, years } \\
\hline $31-40$ & 0.70 & $0.15 / 3.09$ & 0.638 & 0.49 & $0.07 / 3.46$ & 0.509 \\
\hline $41-50$ & 0.24 & $0.06 / 0.94$ & $0.041 *$ & 0.08 & $0.01 / 0.51$ & $0.007 *$ \\
\hline $51-60$ & 0.48 & $0.14 / 1.54$ & 0.219 & 0.20 & $0.04 / 0.95$ & $0.044^{*}$ \\
\hline$>60(\mathrm{REF})$ & - & - & - & - & - & - \\
\hline \multicolumn{7}{|l|}{ Education } \\
\hline Lower secondary school & 0.31 & $0.06 / 1.49$ & 0.147 & 0.17 & $0.03 / 0.99$ & $0.049 *$ \\
\hline Upper secondary school & 0.27 & $0.06 / 1.20$ & 0.087 & 0.12 & $0.02 / 0.65$ & $0.014^{*}$ \\
\hline Bachelors Degree & 0.20 & $0.04 / 0.97$ & $0.046^{*}$ & 0.14 & $0.02 / 0.82$ & $0.030 *$ \\
\hline Postgraduate (REF) & - & - & - & - & - & - \\
\hline Sexual orientation (HETERO vs HOMO) & 1.25 & $0.56 / 2.77$ & 0.584 & - & - & - \\
\hline Stable Relationship (No vs Yes) & 0.91 & $0.40 / 2.04$ & 0.919 & - & - & - \\
\hline Children (No vs Yes ) & 0.45 & $0.19 / 1.08$ & 0.077 & - & - & - \\
\hline \multicolumn{7}{|l|}{ Employment status } \\
\hline Employed & 0.34 & $0.12 / 0.94$ & $0.038 *$ & 0.23 & $0.07 / 0.75$ & $0.016^{*}$ \\
\hline Retired & 0.29 & $0.07 / 1.18$ & 0.086 & 0.12 & $0.01 / 0.79$ & $0.028^{*}$ \\
\hline Unemployed (REF) & - & - & - & - & - & - \\
\hline Years from HIV diagnosis & & & & - & - & - \\
\hline$<5$ years & 1.06 & $0.35 / 3.21$ & 0.910 & - & - & - \\
\hline $5-10$ years & 1.71 & $0.59 / 4.91$ & 0.317 & - & - & - \\
\hline$>10$ years $(\mathrm{REF})$ & - & - & - & - & - & - \\
\hline Time from starting first cART regimen & & & & - & - & - \\
\hline$<5$ years & 1.02 & $0.34 / 3.05$ & 0.971 & - & - & - \\
\hline 5-10 years & 2.10 & $0.77 / 5.70$ & 0.143 & - & - & - \\
\hline$>10$ years $(\mathrm{REF})$ & - & - & - & - & - & - \\
\hline Own viremia knowledge (NO vs YES) & 0.38 & $0.07 / 1.99$ & 0.253 & - & - & - \\
\hline
\end{tabular}


HIV-RNA <50 copies/mL (YES vs NO)

Adherence, on a 0-10 scale

Abbreviations: OR odd ratio, cART combined antiretroviral therapy, CI Confidence Interval, REF reference, IES-R Impact of Event ScaleRevised.

*statistically significant $\mathrm{p}$ values.

Table 3b. Demographic and clinical factors associated to mild-to-severe levels of Depression, Anxiety and Stress measured by DASS-21. 
DAS-21

DASS-21

Depression

subscale

UNIVARIATE

ANALYSIS
MULTIVARIATE

ANALYSIS
Anxiety

subscale

UNIVARIATE

ANALYSIS
Das-21

Stress

subscale

\begin{tabular}{|c|c|c|c|c|c|c|c|c|c|c|c|c|}
\hline Variables & OR & $95 \%$ CI & $\mathrm{p}$ & OR & $95 \%$ CI & $\mathrm{p}$ & OR & $95 \%$ CI & $\mathrm{p}$ & OR & $95 \%$ CI & $\mathrm{p}$ \\
\hline $\begin{array}{l}\text { Sex (Female } \\
\text { vs Male) }\end{array}$ & 0.47 & $0.09 / 2.26$ & 0.347 & - & - & - & 1.91 & $0.50 / 7.21$ & 0.337 & 1.59 & $0.27 / 9.28$ & 0.606 \\
\hline
\end{tabular}

\begin{tabular}{|c|c|c|c|c|c|c|c|c|c|c|c|c|}
\hline $31-40$ & 4.84 & $0.00 / 0.00$ & 0.998 & - & - & - & 2.72 & $0.21 / 34.01$ & 0.436 & 1.34 & $0.00 / 0.00$ & 0.999 \\
\hline $41-50$ & 4.25 & $0.00 / 0.00$ & 0.998 & - & - & - & 2.14 & $0.20 / 22.65$ & 0.526 & 1.46 & $0.00 / 0.00$ & 0.999 \\
\hline $51-60$ & 2.48 & $0.00 / 0.00$ & 0.998 & - & - & - & 1.87 & $0.20 / 17.39$ & 0.580 & 1.15 & $0.00 / 0.00$ & 0.999 \\
\hline$>60(\mathrm{REF})$ & - & - & - & - & - & - & - & - & - & - & - & - \\
\hline
\end{tabular}

Education

Lower

$0.11 \quad 0.01 / 1.28$

$0.079 \quad 0.10 \quad 0.008 / 1.36$

$0.085 \quad 1.42 \quad 0.13 / 15.51$

$\begin{array}{lll}0.769 & 0.43 & 0.02 / 7.66\end{array}$

0.569

secondary

school

Upper

$0.47 \quad 0.09 / 2.29$

$0.351 \quad 0.46 \quad 0.07 / 2.70$

0.392

$1.110 .11 / 11.08$

$\begin{array}{lll}0.928 & 0.52 & 0.04 / 6.40\end{array}$

0.615

secondary

school

Bachelors

$0.56 \quad 0.10 / 3.10$

$0.508 \quad 0.52 \quad 0.08 / 3.37$

$0.498 \quad 1.50 \quad 0.13 / 16.32$

$\begin{array}{lll}0.739 & 0.95 & 0.07 / 11.78\end{array}$

0.970

Degree

Postgraduate

(REF)

Sexual

$$
\begin{array}{lll}
0.58 & 0.18 / 1.88 & 0.367
\end{array}
$$

$2.15 \quad 0.58 / 7.89$

$0.247 \quad 2.38 \quad 0.41 / 13.65$

0.330

orientation

(HETERO vs

HOMO)

Stable

$0.43 \quad 0.13 / 1.38$

$0.439-\quad-$

$0.77 \quad 0.21 / 2.72$

$\begin{array}{lll}0.685 & 0.64 & 0.12 / 3.36\end{array}$

0.601

Relationship

(No vs Yes)

Children (No $\quad 0.80 \quad 0.24 / 2.64$

0.807

$0.330 .09 / 1.20$

$\begin{array}{lll}0.093 & 0.20 & 0.03 / 1.20\end{array}$

0.079

vs Yes)

Employment

status 


\begin{tabular}{|c|c|c|c|c|c|c|c|c|c|c|c|c|}
\hline Employed & 0.54 & $0.15 / 1.87$ & 0.335 & - & - & - & 0.51 & $0.13 / 2.03$ & 0.346 & 0.34 & $0.06 / 1.84$ & 0.214 \\
\hline Retired & 0.27 & $0.02 / 1.66$ & 0.266 & - & - & - & 0.36 & $0.03 / 3.65$ & 0.391 & 0.00 & $0.00 / 0.00$ & 0.999 \\
\hline $\begin{array}{l}\text { Unemployed } \\
\text { (REF) }\end{array}$ & - & - & - & - & - & - & - & - & - & - & - & - \\
\hline \multicolumn{13}{|l|}{ Years from } \\
\hline \multicolumn{13}{|l|}{ HIV } \\
\hline \multicolumn{13}{|l|}{ diagnosis } \\
\hline$<5$ years & 3.46 & $0.69 / 17.36$ & 0.131 & 2.97 & $0.55 / 15.84$ & 0.202 & 1.38 & $0.25 / 7.58$ & 0.710 & 4.42 & $0.57 / 34.19$ & 0.154 \\
\hline $5-10$ years & 9.54 & $2.38 / 38.19$ & $0.001 *$ & 10.02 & $2.49 / 41.95$ & $0.002 *$ & 1.93 & $0.43 / 8.64$ & 0.388 & 3.87 & $0.50 / 29.66$ & 0.192 \\
\hline $\begin{array}{l}>10 \quad \text { years } \\
(\mathrm{REF})\end{array}$ & - & - & - & - & - & - & - & - & - & - & - & - \\
\hline \multicolumn{13}{|l|}{$\begin{array}{l}\text { Time from } \\
\text { starting first }\end{array}$} \\
\hline $\begin{array}{l}\text { cART } \\
\text { regimen }\end{array}$ & & & & & & & & & & & & \\
\hline$<5$ years & 2.94 & $0.59 / 14.7$ & 0.188 & - & - & - & 1.17 & $0.21 / 6.44$ & 0.850 & 3.80 & $0.49 / 29.24$ & 0.200 \\
\hline $5-10$ years & 6.41 & $1.65 / 24.86$ & $0.007^{*}$ & - & - & - & 1.39 & $0.31 / 6.13$ & 0.660 & 2.85 & $0.37 / 21.59$ & 0.311 \\
\hline $\begin{array}{l}>10 \quad \text { years } \\
(\mathrm{REF})\end{array}$ & - & - & - & - & - & - & - & - & - & - & - & - \\
\hline $\begin{array}{l}\text { Own viremia } \\
\text { knowledge } \\
\text { (NO vs YES) }\end{array}$ & 0.84 & $0.09 / 7.45$ & 0.880 & - & - & - & 6.15 & $1.23 / 30.61$ & 0.027 & 2.42 & $0.24 / 23.77$ & 0.446 \\
\hline $\begin{array}{l}\text { HIV-RNA } \\
<50 \\
\text { copies/mL } \\
\text { (YES vs NO) }\end{array}$ & 2.26 & $0.47 / 10.89$ & 0.309 & - & - & - & 2.86 & $0.00 / 0.00$ & 0.998 & 1.44 & $0.00 / 0.00$ & 0.998 \\
\hline $\begin{array}{l}\text { Adherence, } \\
\text { on a 0-10 } \\
\text { scale }\end{array}$ & 0.95 & $0.58 / 1.54$ & 0.851 & - & - & - & 1.21 & $0.56 / 2.62$ & 0.620 & 2.16 & $0.35 / 13.38$ & 0.405 \\
\hline
\end{tabular}

Abbreviations: OR odd ratio, cART combined antiretroviral therapy, CI Confidence Interval, REF reference, DASS-21 Depression, Anxiety and Stress Scale.

*statistically significant $\mathrm{p}$ values.

Table 4

Description of contact history and physical health status. 


\begin{tabular}{|c|c|}
\hline Variables & $\mathrm{N}(\%)$ \\
\hline Contacts with individuals & $4(4.1)$ \\
\hline with confirmed COVID-19 infection & \\
\hline Contacts with individuals & $4(4.1)$ \\
\hline with suspected COVID-19 infection & \\
\hline Contact with infected materials & $7(7.1)$ \\
\hline Consultation with a doctor & $19(19.4)$ \\
\hline Hospitalization & $1(1)$ \\
\hline Testing for COVID-19 & $5(5.1)$ \\
\hline Quarantine & $2(2)$ \\
\hline \multicolumn{2}{|l|}{ Self rating health status } \\
\hline Poor & $0(0)$ \\
\hline Passable & $10(10.2)$ \\
\hline Good & $46(46.9)$ \\
\hline Very good & $30(30.6)$ \\
\hline Excellent & $12(12.2)$ \\
\hline Total physical symptoms & - \\
\hline Fever & $8(8.2)$ \\
\hline Chills & $18(18.4)$ \\
\hline Headache & $33(33.7)$ \\
\hline Myalgia & $18(18.4)$ \\
\hline Cough & $10(10.2)$ \\
\hline Breathing difficulty & $5(5.1)$ \\
\hline Dizziness & $3(3.1)$ \\
\hline Coryza & $11(11.2)$ \\
\hline Sore throat & $10(10.2)$ \\
\hline Triad of symptoms & $1(1)$ \\
\hline
\end{tabular}

Abbreviations: N number

Table 5. Physical Symptoms associated to mild-to-extremely severe levels of distress measured by IES-R and mild-to-severe levels of depression, anxiety and stress measured by DASS-21

IES-R TOT DASS-21 Depression subscale DASS-21 Anxiety subscale DASS-21 Stress subscale 


\begin{tabular}{|c|c|c|c|c|c|c|c|c|c|c|c|c|}
\hline Variables & OR & $95 \%$ CI & $\mathrm{p}$ & OR & $95 \% \mathrm{CI}$ & $\mathrm{p}$ & OR & $95 \% \mathrm{CI}$ & $\mathrm{p}$ & OR & $95 \% \mathrm{CI}$ & $\mathrm{p}$ \\
\hline Fever (YES vs NO) & 10.02 & $1.18 / 84.96$ & $0.034 *$ & 0.84 & $0.09 / 7.45$ & 0.880 & 1.14 & $0.12 / 10.27$ & 0.905 & 2.42 & $0.24 / 23.77$ & 0.446 \\
\hline Chills (YES vs NO) & 3.00 & $1.02 / 8.81$ & $0.046^{*}$ & 2.00 & $0.54 / 7.29$ & 0.294 & 2.98 & $0.76 / 11.55$ & 0.114 & 5.13 & $0.94 / 27.90$ & 0.058 \\
\hline Headache (YES vs & 2.17 & $0.92 / 5.09$ & 0.075 & 4.50 & $1.36 / 14.81$ & $0.013 *$ & 6.61 & $1.62 / 26.97$ & $0.008 *$ & 4.34 & $0.75 / 25.08$ & 0.101 \\
\hline \multicolumn{13}{|l|}{ NO) } \\
\hline Myalgia (YES vs & 3.00 & $1.02 / 8.81$ & $0.046^{*}$ & 4.50 & $1.32 / 15.27$ & $0.016 *$ & 4.74 & $1.26 / 17.84$ & $0.021 *$ & 5.13 & $0.94 / 27.90$ & 0.058 \\
\hline \multicolumn{13}{|l|}{ NO) } \\
\hline Cough (YES vs NO) & 1.97 & $0.52 / 7.49$ & 0.318 & 1.58 & $0.30 / 8.36$ & 0.589 & 0.86 & $0.09 / 7.57$ & 0.897 & 1.84 & $0.19 / 17.57$ & 0.595 \\
\hline $\begin{array}{l}\text { Breathing difficulty } \\
\text { (YES vs NO) }\end{array}$ & 5.30 & $0.57 / 49.26$ & 0.143 & 4.50 & $0.68 / 29.76$ & 0.119 & 15.93 & $2.31 / 109.85$ & $0.005 *$ & 4.40 & $0.41 / 47.03$ & 0.220 \\
\hline Dizziness (YES vs & 2.12 & $0.00 / 0.00$ & 0.999 & 13.83 & $1.16 / 164.46$ & $0.038 *$ & 4.25 & $0.35 / 51.17$ & 0.254 & 9.00 & $0.69 / 116.86$ & 0.093 \\
\hline \multicolumn{13}{|l|}{ NO) } \\
\hline Coryza (YES vs NO) & 1.02 & $0.29 / 3.61$ & 0.969 & 1.38 & $0.26 / 7.22$ & 0.696 & 0.77 & $0.08 / 6.66$ & 0.812 & 1.64 & $0.17 / 15.48$ & 0.666 \\
\hline $\begin{array}{l}\text { Sore throat (YES vs } \\
\text { NO) }\end{array}$ & 1.25 & $0.33 / 4.65$ & 0.733 & 0.64 & $0.07 / 5.49$ & 0.685 & 2.19 & $0.40 / 11.96$ & 0.364 & 1.84 & $0.19 / 17.57$ & 0.595 \\
\hline Triad & 2.02 & $0.00 / 0.00$ & 1.000 & 0.00 & $0.00 / 0.00$ & 1.000 & 0.00 & $0.00 / 0.00$ & 1.000 & 0.00 & $0.00 / 0.00$ & 1.000 \\
\hline symptoms(YES vs & & & & & & & & & & & & \\
\hline NO) & & & & & & & & & & & & \\
\hline
\end{tabular}

Abbreviations: OR odd ratio, $\mathrm{N}=$ number, REF reference, CI Confidence Interval, IES-R Impact of Event Scale-Revised, DASS-21 Depression, Anxiety and Stress Scale.

*statistically significant $\mathrm{p}$ values.

\section{Table 6}

Description of Knowledge and Concerns about COVID-19. 


\begin{tabular}{|c|c|}
\hline Variables & $\mathrm{N}(\%)$ or median* (IQR) \\
\hline Habit of keeping informed about pandemic trend & $92(93.9)$ \\
\hline \multicolumn{2}{|l|}{ Main source of health information } \\
\hline Television & $58(59.2)$ \\
\hline Internet & $34(34.7)$ \\
\hline Radio & $3(3.1)$ \\
\hline Other sources & $3(3.1)$ \\
\hline \multicolumn{2}{|l|}{ Route of transmission through droplets } \\
\hline Agree & $85(86.7)$ \\
\hline Disagree & $2(2)$ \\
\hline Do not know & $11(11.2)$ \\
\hline \multicolumn{2}{|l|}{ Route of transmission through contaminated objects } \\
\hline Agree & $83(84.7)$ \\
\hline Disagree & $6(6.1)$ \\
\hline Do not know & $9(9.2)$ \\
\hline Satisfaction with amount of health information* & $7(5-8)$ \\
\hline \multicolumn{2}{|l|}{ Likelihood of surviving if infected withCOVID-19 } \\
\hline no chance & $0(0)$ \\
\hline unlikely & $1(1)$ \\
\hline likely & $8(8.2)$ \\
\hline very likely & $60(61.2)$ \\
\hline highly likely & $29(29.6)$ \\
\hline Level of confidence in the own doctor's ability to diagnose* & $8(7-10)$ \\
\hline Concern about COVID-19 situation in Italy* & $7(5-8)$ \\
\hline Concern about contracting COVID-19* & $6(5-8)$ \\
\hline Concern about other family members getting COVID-19* & $8(5-9)$ \\
\hline \multicolumn{2}{|l|}{ Feeling too much unnecessary worry about the pandemic } \\
\hline always & $21(21.4)$ \\
\hline most of times & $15(15.3)$ \\
\hline sometimes & 36 (36.7) \\
\hline occasionally & $14(14.3)$ \\
\hline never & $12(12.2)$ \\
\hline
\end{tabular}

Abbreviations: N number, IQR Interquartile Range

Table 7

Precautionary measures adopted by participants. 


\begin{tabular}{lc}
\hline Variables & $\mathrm{N}(\%)$ \\
\hline hand hygiene with soap and water & $82(83.7)$ \\
Always & $14(14.3)$ \\
\hline Most of the time & $1(1)$ \\
\hline Sometimes & $1(1)$ \\
\hline Occasionally & $0(0)$
\end{tabular}

hand hygiene immediately after coughing, rubbing nose or sneezing

\begin{tabular}{lc}
\hline Always & $42(42.9)$ \\
\hline Most of the time & $32(32.7)$ \\
Sometimes & $17(17.3)$ \\
\hline Occasionally & $5(5.1)$ \\
Never & $2(2)$
\end{tabular}

hand hygiene after touching contaminated objects

\begin{tabular}{lc} 
Always & $79(80.6)$ \\
\hline Most of the time & $15(15.3)$ \\
\hline Sometimes & $3(3.1)$ \\
\hline Occasionally & $1(1)$ \\
\hline Never & $0(0)$
\end{tabular}

Avoiding sharing of utensils during meals

\begin{tabular}{|c|c|}
\hline Always & $68(69.4)$ \\
\hline Most of the time & $16(16.3)$ \\
\hline Sometimes & $9(9.2)$ \\
\hline Occasionally & $2(2.0)$ \\
\hline Never & $3(3.1)$ \\
\hline \multicolumn{2}{|c|}{ Covering mouth when coughing and sneezing } \\
\hline Always & 77(78.6) \\
\hline Most of the time & $20(20.4)$ \\
\hline Sometimes & $1(1)$ \\
\hline Occasionally & $0(0)$ \\
\hline Never & $0(0)$ \\
\hline \multicolumn{2}{|c|}{ Wearing mask regardless of the presence or absence of symptoms } \\
\hline Always & $63(64.3)$ \\
\hline Most of the time & $33(33.7)$ \\
\hline Sometimes & $0(0)$ \\
\hline Occasionally & $2(2)$ \\
\hline Never & $0(0)$ \\
\hline \multicolumn{2}{|c|}{ Average number of hours staying at home per day } \\
\hline 0-9 hours per day & $21(21.4)$ \\
\hline 10-19 hours per day & $48(49)$ \\
\hline 20-24 hours per day & $29(29.6)$ \\
\hline
\end{tabular}

Abbreviations: $\mathrm{N}$ number 
Table 8

Additional information required with respect to COVID-19.

\begin{tabular}{ll}
\hline Variables & $\mathrm{N}(\%)$ \\
\hline Information about the global trend of pandemic & $42(42.9)$ \\
More details on symptoms & $38(38.8)$ \\
\hline Advices on prevention & $38(38.8)$ \\
\hline Information about routes of transmission & $51(52.0)$ \\
\hline Information about treatment & $63(64.3)$ \\
\hline Information about availability of medicines/vaccines & $63(64.3)$ \\
\hline Updates on the state of pandemic in their location & $45(45.9)$ \\
\hline Number of people infected in their location & $49(50)$ \\
\hline Management in foreign countries & $45(45.9)$ \\
\hline Tips for moving from home safely & $34(34.7)$ \\
\hline
\end{tabular}

Abbreviations: $\mathrm{N}$ number

\section{Supplementary Files}

This is a list of supplementary files associated with this preprint. Click to download.

- S1.doc

- S2.doc

- S3.doc

- S4.doc

- S5.doc 